Document downloaded from:

http://hdl.handle.net/10251/144822

This paper must be cited as:

Flores-Lasluisa, JX.; Huerta, F.; Cazorla-Amoros, D.; Morallón, E. (15-1). Structural and morphological alterations induced by cobalt substitution in LaMnO3 perovskites. Journal of Colloid and Interface Science. 556:658-666. https://doi.org/10.1016/j.jcis.2019.08.112

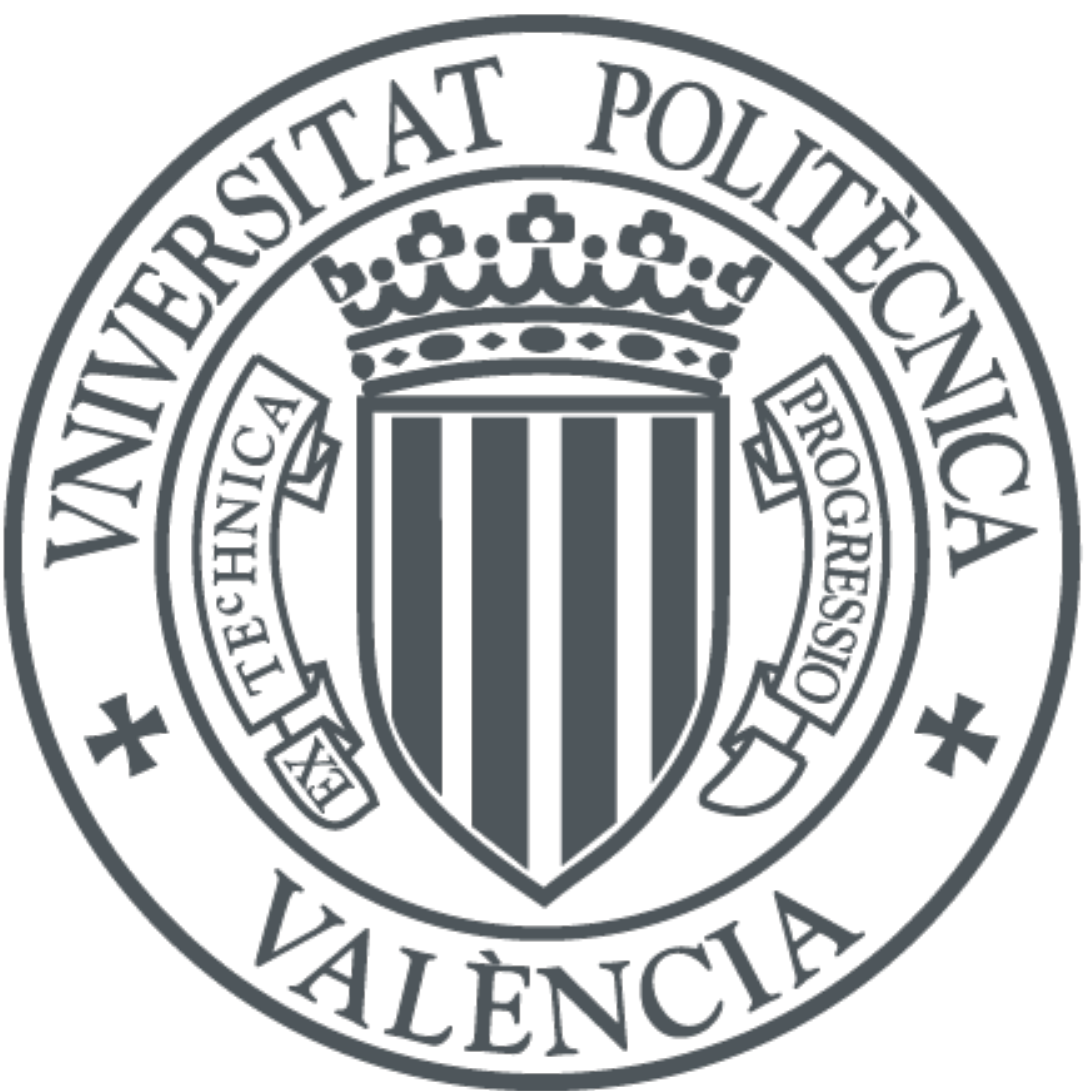

The final publication is available at

https://doi.org/10.1016/j.jcis.2019.08.112

Copyright Elsevier

Additional Information 


\title{
Structural and Morphological Alterations Induced by Cobalt Substitution in $\mathrm{LaMnO}_{3}$ Perovskites
}

\author{
J. X. Flores-Lasluisa ${ }^{1}$, F. Huerta ${ }^{2}$, D. Cazorla-Amorós ${ }^{3}$, E. Morallón ${ }^{1}$
}

${ }^{1}$ Dept. Química Física e Instituto Universitario de Materiales, Universidad de Alicante, Ap. 99, E-03080, Alicante, Spain

${ }^{2}$ Dept. Ingenieria Textil y Papelera, Universitat Politecnica de Valencia, Plaza Ferrandiz y Carbonell, 1. E-03801, Alcoy, Spain

${ }^{3}$ Dept. Química Inorgánica e Instituto Universitario de Materiales, Universidad de Alicante, Ap. 99, E-03080, Alicante, Spain

\begin{abstract}
The chemical composition of a $\mathrm{LaMnO}_{3}$ perovskite was modified sequentially by an improved sol-gel method to include cobalt centers in some B sites formerly occupied by $\mathrm{Mn}$. In this way, a representative set of materials of general formula $\mathrm{LaMn}_{1-\mathrm{x}} \mathrm{Co}_{\mathrm{x}} \mathrm{O}_{3}$ was obtained whose composition extends from $\mathrm{LaMnO}_{3}$ to $\mathrm{LaCoO}_{3}$. These perovskites, as promising materials for oxygen reduction or oxygen evolution reactions, were characterized by several imaging (SEM), spectroscopic (XPS, EDX) and diffraction (XRD) techniques to elucidate their structure and to demonstrate the existence of composition differences between the catalytic surface and the bulk material. Specifically, it was found that lanthanum ions prevail at the surface of the catalyst but high cobaltsubstitution levels stimulate the surface enrichment in B cations in their respective higher oxidation states $\left(\mathrm{Mn}^{4+}\right.$ and $\mathrm{Co}^{3+}$ against $\mathrm{Mn}^{3+}$ and $\left.\mathrm{Co}^{2+}\right)$. This phenomenon opens the possibility of tuning their electrocatalytic properties and to synthesize suitable materials for electrochemical reactions involving molecular oxygen.
\end{abstract}

Keywords: $\mathrm{LaMnO}_{3}$ sol-gel synthesis, Cobalt-induced changes, Structural analysis, Materials for ORR and OER. 


\section{Introduction}

Perovskite-type materials constitute a wide family of inorganic compounds showing related crystallographic structures and diverse chemical composition, which are based on the general formula $\mathrm{ABX}_{3}$. During the past few years, perovskites have received considerable attention from diverse scientific disciplines such as chemistry, materials science or physics because of their multiple and interesting physicochemical properties, mechanical and chemical stability and moderate production costs [1]. Another key feature of these materials, which makes them attractive for research purposes, is the possibility of tuning their composition and morphology to show (or improve) electrical conductivities [2], optical band gaps [3,4], magnetic responses [5], catalytic properties[6] or adsorption capabilities [7].

Perovskites show also promising applications in electrochemistry [8-10] and, more specifically, in renewable energy sources such as fuel cells and metal-air batteries. It is believed that both systems will play strategic roles in electrochemical energy conversion to meet future energy requirements of society [11]. However, the current performance of these devices is strongly limited by the sluggish electrochemical reactions implying molecular oxygen: the oxygen reduction reaction (ORR) and the oxygen evolution reaction (OER). Classical electrocatalysts for the ORR are constituted, on the one hand, by platinum-based materials, such as the alloys of this noble metal with others like Ag, $\mathrm{Pd}$, and Ni that enhance activity and/or stability and, on the other, by catalysts made of platinum-based nanomaterials supported on carbon materials, which improve the surface area of the electrocatalyst and increase the overall efficiency of ORR [12-15]. Unfortunately, these ORR catalysts do not offer good catalytic activity toward the OER reaction (and vice versa). Consequently, for OER other materials like $\mathrm{RuO}_{2}$ and $\mathrm{IrO}_{2}$ oxides are preferred, despite they are high-price compounds with limited availability. To lower the cost of these materials, some authors proposed that they can be used as nanoparticles supported on carbon materials. Taking into account both stability and activity of the electrocatalyst, $\mathrm{IrO}_{2}$ nanoparticles seem to exhibit the best performance toward OER $[16,17]$. 
Perovskite oxides based on the $\mathrm{ABO}_{3}$ crystal structure, where $\mathrm{A}$ is a rare earth metal or an alkaline earth metal cation and B is a transition metal cation, were proposed during the last years as efficient bifunctional electrocatalysts for both ORR and OER reactions. This is because they are low-cost materials whose electrocatalytic properties can be tuned to exhibit a better performance toward these reactions [18-24]. Particularly, a set of lanthanoid-metals manganites were used to prove that the size of A cation plays a role in oxygen reduction [25]. Decreasing the ionic radius produces a reduction in the Goldschmidt's tolerance factor and, as a consequence, less symmetrical structures are formed. In those structures, the octahedral $\mathrm{BO}_{6}$ presents both distortion and rotation that are more important when smaller A-site cations are used. This increases the electrical resistivity and therefore the overall catalytic activity toward oxygen reduction is affected $[5,26]$. In octahedral $\mathrm{BO}_{6}$ each cation is surrounded by six oxygen anions and, according to the crystal field theory (CFT), $d$-orbitals split into a lower group of three $t_{2 g}$ and a highest group of two $e_{g}$ energy orbitals [27]. On the contrary, transition metals at the surface of the compound adopt a square pyramidal symmetry, where a B cation is surrounded only by five $\mathrm{O}$ anions, so reactants and products of ORR/OER can interact with the empty position. Among lanthanoid-metals, the $\mathrm{La}^{3+}$ cation, apart from its optimum size, provides perovskites with higher electron conductivity and, consequently, offers the best performance of the metal series toward ORR [28].

In fact, La-based perovskite oxides, $\mathrm{LaBO}_{3}$, have been intensively studied as electrocatalysts for reactions involving molecular oxygen. It was suggested that enhancing the ORR and OER activity requires, on the one hand, an intensification of the covalency between transition metal orbitals and molecular oxygen orbitals in the perovskite and, on the other, the filling of $e_{g}$ orbitals at B surface cations with approximately one electron [29-32]. Empty or fully occupied $e_{g}$ orbitals are not desirable because a strong or weak bonding, respectively, is produced between the B site and the oxygen species. This affects the rate limit steps in ORR/OER and, consequently, deteriorates the overall activity of the material. The most representative $\mathrm{B}$ cations explored for these systems include $3 d$ metals such as $\mathrm{Cr}, \mathrm{Mn}, \mathrm{Fe}, \mathrm{Co}$, and Ni. Sunarso et al. [33] reported that the perovskite based on Co exhibits the largest current density and the most positive onset potential for oxygen reduction, whereas other perovskites offer a similar onset potential but with a different current density in the order $\mathrm{Mn}>\mathrm{Ni}>\mathrm{Fe}>\mathrm{Cr}$. 
On the contrary, Celorrio et al. [34] found that $\mathrm{LaMnO}_{3}$ perovskite shows both the most positive onset potential and the largest current density. Similar behavior was observed by Ashok et al. [35], which pointed out that the performance toward ORR decreases in the order $\mathrm{LaMnO}_{3}>\mathrm{LaCoO}_{3}>\mathrm{LaNiO}_{3}>\mathrm{LaFeO}_{3}>\mathrm{LaCrO}_{3}$, although the latter oxide material exhibited better cycling stability in ORR and displayed good activity toward OER, thus showing better bifunctionality than the others.

The bifunctional catalytic activity in compounds related with $\mathrm{LaBO}_{3}$ can be tailored by means of a partial substitution of B cations. It was reported that substitution influences significantly the electrochemical response of the material. This is due to some combined effects, such as the occurrence of synergy between the two cations, the induction of altered (and more favorable) arrangements in the resulting compound like porous structures that facilitate the diffusion of electrolyte or oxygen into the perovskite material or the formation of additional metal redox pairs [36,37]. Recent studies on $\mathrm{LaMn}_{1-\mathrm{x}} \mathrm{Co}_{\mathrm{x}} \mathrm{O}_{3}$ electrocatalysts were carried out by supporting these materials on different carbon structures to enhance their electrocatalytic properties toward ORR and OER [38-41]. Hu et al. [38] and Lee et al. [40] observed that little substitution of cobalt for Mn makes the $\mathrm{LaMn}_{0.9} \mathrm{Co}_{0.1} \mathrm{O}_{3}$ perovskite exhibit a better performance toward ORR with a more positive onset potential and a larger current density than $\mathrm{LaMnO}_{3}$. This effect seems related to the occupancy of $e_{g}$, that approaches to the desirable unity. In addition, the new oxygen vacancies formed facilitate oxygen diffusion and the electrical conductivity increases after the introduction of cobalt. Besides, the produced $\mathrm{Mn}^{4+}$ species provides higher oxidation capability than the original $\mathrm{Mn}^{3+}$. On the contrary, Liu et al. [39] reported that the catalytic activity of the undoped perovskite is higher and, for similar cobalt and manganese content, such catalytic activity decreases drastically due to the alterations induced in the crystal structure by the smaller cation. Nevertheless, they found that the activity toward OER enhances after the introduction of cobalt and reported that $\mathrm{LaMn}_{0.7} \mathrm{Co}_{0.3} \mathrm{O}_{3}$ perovskite shows the best response toward OER, so this material was suggested as a promising bifunctional electrocatalyst. It can be then concluded that oxygen vacancies resulting from moderate replacement of $\mathrm{Mn}^{3+}$ by $\mathrm{Co}^{2+}$ will facilitate the proliferation of B surface cations and, consequently, an increase in the population of $\mathrm{B}^{\mathrm{m}+1} / \mathrm{B}^{\mathrm{m}}$ redox pairs will take place, thus promoting the catalytic activity for ORR/OER with no other detrimental effects. 
In line with the above premises, the overall goal of this work is to synthesize an improved bifunctional electrocatalyst based on $\mathrm{LaMnO}_{3}$ perovskite structure. The experimental strategy consists in making a sequential replacement of manganese atoms by cobalt centers in order to modify gradually the structure and morphology of the materials. Diverse synthesis procedures have been proposed to obtain perovskites such as hydrothermal, coprecipitation, auto-combustion, solid-state or sol-gel synthesis, but the method employed in this work to prepare $\mathrm{LaMn}_{1-\mathrm{x}} \mathrm{Co}_{\mathrm{x}} \mathrm{O}_{3}$ materials was a modified solgel route that employs two different chelating agents. This modification makes more likely to produce symmetrical structures, which is one of the key factors that improves the electrocatalytic activity toward oxygen reactions. Hence, a complete set of $\mathrm{LaMn}_{1-}$ ${ }_{x} \mathrm{Co}_{\mathrm{x}} \mathrm{O}_{3}$ materials (x ranging from 0 to 1 ) will be firstly synthesized and, then, extensively characterized by different spectroscopic and microscopic techniques. In a forthcoming contribution, these perovskite materials will be analyzed from the electrochemical perspective to test the effect of both structure and composition on ORR and OER and to find the best compromise between catalytic activity and electrochemical stability.

\section{Experimental}

\subsection{Materials and reagents}

Reagents used in this work were lanthanum (III) nitrate hexahydrate $\left(\mathrm{La}\left(\mathrm{NO}_{3}\right)_{3} \cdot 6 \mathrm{H}_{2} \mathrm{O}\right)$ (Sigma-Aldrich, 99.99\%), manganese (II) nitrate hydrate $\left(\mathrm{Mn}\left(\mathrm{NO}_{3}\right)_{2} \cdot \mathrm{xH}_{2} \mathrm{O}\right)($ Alfa Aesar, 99.98\%), cobalt (II) nitrate hexahydrate $\left(\mathrm{Co}\left(\mathrm{NO}_{3}\right)_{2} \cdot 6 \mathrm{H}_{2} \mathrm{O}\right)$ (Sigma-Aldrich, ACS reagent), citric acid (Sigma-Aldrich 99\%), ethylenediaminetetraacetic acid (EDTA) (Sigma-Aldrich, ACS reagent) and ammonia $\left(\mathrm{NH}_{3}\right)$ (VWR Chemicals, analytic reagent). All these chemicals were used with no further purification.

\subsection{Synthesis procedure}

The synthesis of $\mathrm{LaMn}_{1-\mathrm{x}} \mathrm{Co}_{\mathrm{x}} \mathrm{O}_{3}$ perovskites (x ranging from 0 to 1 ) was performed by a sol-gel method similar to that described in the literature [42] but modified by the addition of cobalt. The mass of reagents was adjusted to obtain 1.0 gram of product, employing a 2:3:1:1 molar ratio for EDTA, citric acid, $\mathrm{La}\left(\mathrm{NO}_{3}\right)_{3} \cdot 6 \mathrm{H}_{2} \mathrm{O}$ and the sum of 
$\mathrm{Mn}\left(\mathrm{NO}_{3}\right)_{2} \cdot \mathrm{xH}_{2} \mathrm{O}$ (assumed $\mathrm{x}=4$ ) and $\mathrm{Co}\left(\mathrm{NO}_{3}\right)_{2} \cdot 6 \mathrm{H}_{2} \mathrm{O}$, respectively. First, EDTA was dissolved in a mixture of $41 \mathrm{~mL}$ deionized water and $3.3 \mathrm{~mL} \mathrm{NH}_{3}$. The stoichiometric amounts of metal precursors and citric acid were added to the EDTA solution. $\mathrm{NH}_{3}$ was slowly dropped into the solution to set the $\mathrm{pH}$ at 9 to form a stable sol complex. Then, the solution was stirred at $80^{\circ} \mathrm{C}$ for $6 \mathrm{~h}$ and subsequently dried at $150{ }^{\circ} \mathrm{C}$ for $12 \mathrm{~h}$ in the stove to obtain the gel. Then, the gel was heated at $500{ }^{\circ} \mathrm{C}$ for $30 \mathrm{~min}$ until a fluffy product was obtained. Finally, this product was ground and calcined at $700{ }^{\circ} \mathrm{C}$ for $6 \mathrm{~h}$ to form the perovskite oxide materials.

\subsection{Characterization techniques}

Perovskites were characterized by $\mathrm{X}$-ray diffraction (XRD) using $\mathrm{Cu} \mathrm{K} \alpha$ radiation source at a step of $0.05^{\circ}$ in the $2 \theta$ range from $10^{\circ}$ to $80^{\circ}$ on a Bruker D8-Advance diffractometer (Billerica, USA) with a Goebel mirror (non-planar samples) and high temperature chamber (up to $900{ }^{\circ} \mathrm{C}$ ) with a X-ray generator KRISTALLOFLEX K 760-80F (power: $3000 \mathrm{~W}$, voltage: $20-60 \mathrm{kV}$ and current: $5-80 \mathrm{~mA}$ ). The detection limit is around $1 \%$. The crystallite sizes were estimated by applying the Scherrer equation [43]:

$$
\mathrm{D}_{\mathrm{c}}=\frac{\mathrm{k} \lambda}{\beta \cos (\theta)}
$$

where $D_{c}$ is the crystallite size $(n m)$; $k$ is the constant related to the shape of the grain whose value is $0.89 ; \lambda$ is the wavelength of the radiation source used, which is 0.15406 $\mathrm{nm} ; \beta$ corresponds to the full width at half maximum (FWHM) (radians), and $\theta$ is the Bragg angle. To subtract the instrumental broadening factor from the measured FWHM value, a crystalline quartz pattern was used. The corrected FWHM value of the sample was calculated according to the following equation [44]:

$$
\beta_{\text {real }}^{2}=\beta_{\text {obs }}^{2}-\beta_{\text {inst }}^{2}
$$

where $\beta_{\text {real }}$ is the value obtained only from the crystal size, $\beta_{\text {obs }}$ is the measured value, and $\beta_{\text {inst }}$ is the broadening related to the instrument obtained from the pattern.

The surface composition of the samples was investigated by X-ray photoelectron spectroscopy (XPS) in a VG-Microtech Multilab 3000 equipment (Thermo-Scientific, Waltham, MA, USA), equipped with an $\mathrm{Al} \mathrm{K} \alpha$ radiation source $(1253.6 \mathrm{eV})$. Deconvolution of the XPS data was done with XPSPEAK41 software, experimental 
curves were adjusted by a combination of Lorentz-Gaussian functions and a Shirley line was used as the background. The morphologies and microstructures of the samples were characterized by transmission electron microscopy (TEM, JEOL-2010, $200 \mathrm{kV}$ accelerating voltage, Akishima, Japan), and scanning electron microscopy (SEM, Hitachi S-3000N, Chiyoda, Japan). The TEM microscope is equipped with an OXFORD X-ray detector model INCA Energy TEM 100 for microanalysis (EDX). The image acquisition camera was supplied by GATAN (model ORIUS SC600). It is assembled on the axis with the microscope at the bottom and is integrated into the GATAN Digital Micrograph 1.80.70 image acquisition and processing program for GMS 1.8.0. The equipment has a point-to-point resolution of $0.19 \mathrm{~nm}$ and an information limit of $0.1 \mathrm{~nm}$. The SEM microscope features an X-ray detector from the brand Bruker model XFlash 3001 (Billerica, USA) that can be used to microanalysis (EDX) and mapping. It also offers a variable pressure working mode to observe non-conductive samples without the need to cover them with conductive materials. The equipment has a resolution of $3.5 \mathrm{~nm}$ in vacuum. The bulk composition of perovskites was analyzed by energy-dispersive X-ray spectroscopy (EDX) with the X-ray detector device attached to the SEM microscope.

\section{Results and Discussion}

\subsection{Surface morphology analysis}

Porous structures are desirable for electrocatalytic applications because they facilitate the diffusion of electrolyte ions and solvents into the material, thus providing more active catalytic sites. In this context, $\mathrm{LaMn}_{1-\mathrm{x}} \mathrm{Co}_{\mathrm{x}} \mathrm{O}_{3}$ perovskites are expected to present an appropriate porosity due to the calcination process employed during the synthesis, which removes both EDTA and citric acid from the structure and promotes the thermal decomposition of nitrate [45]. The surface morphology of a set of $\mathrm{LaMn}_{1-\mathrm{x}} \mathrm{Co}_{\mathrm{x}} \mathrm{O}_{3}$ perovskites, with $\mathrm{x}=0,0.2,0.8$ and 1 , was examined by SEM microscopy and the results are presented in Fig. 1.

The first image of the series (that obtained for a pristine $\mathrm{LaMnO}_{3}$ ) shows perovskite particles of polyhedral shape and variable size, ranging roughly between 10 and $300 \mu \mathrm{m}$. Cobalt substitution (images $b$ to $d$ ) has a clear effect on the catalyst morphology, irrespective of the Co content. On the one hand, the particles are of smaller size (of about 
2-10 $\mu \mathrm{m}$ in average) and, on the other hand, their size distribution is much more homogenous than in Fig. 1a. The insets to the main images in Fig.1 show magnified views for each perovskite, for which similar honeycomb-like morphology can be observed. These structures consist on nanoparticles of about $100 \mathrm{~nm}$ in size which appear aggregated forming channels and pores of different diameters, typically under $500 \mathrm{~nm}$. Li et al. [42] reported similar type of structures for a $\mathrm{LaMnO}_{3}$ perovskite synthesized by the sol-gel method. It should be noted that particles in Fig. 1 appear more individually defined at higher cobalt substitution, so the crystallinity of the material could be affected by the relative content of cobalt. We will discuss this point later, in the light of XRD results.
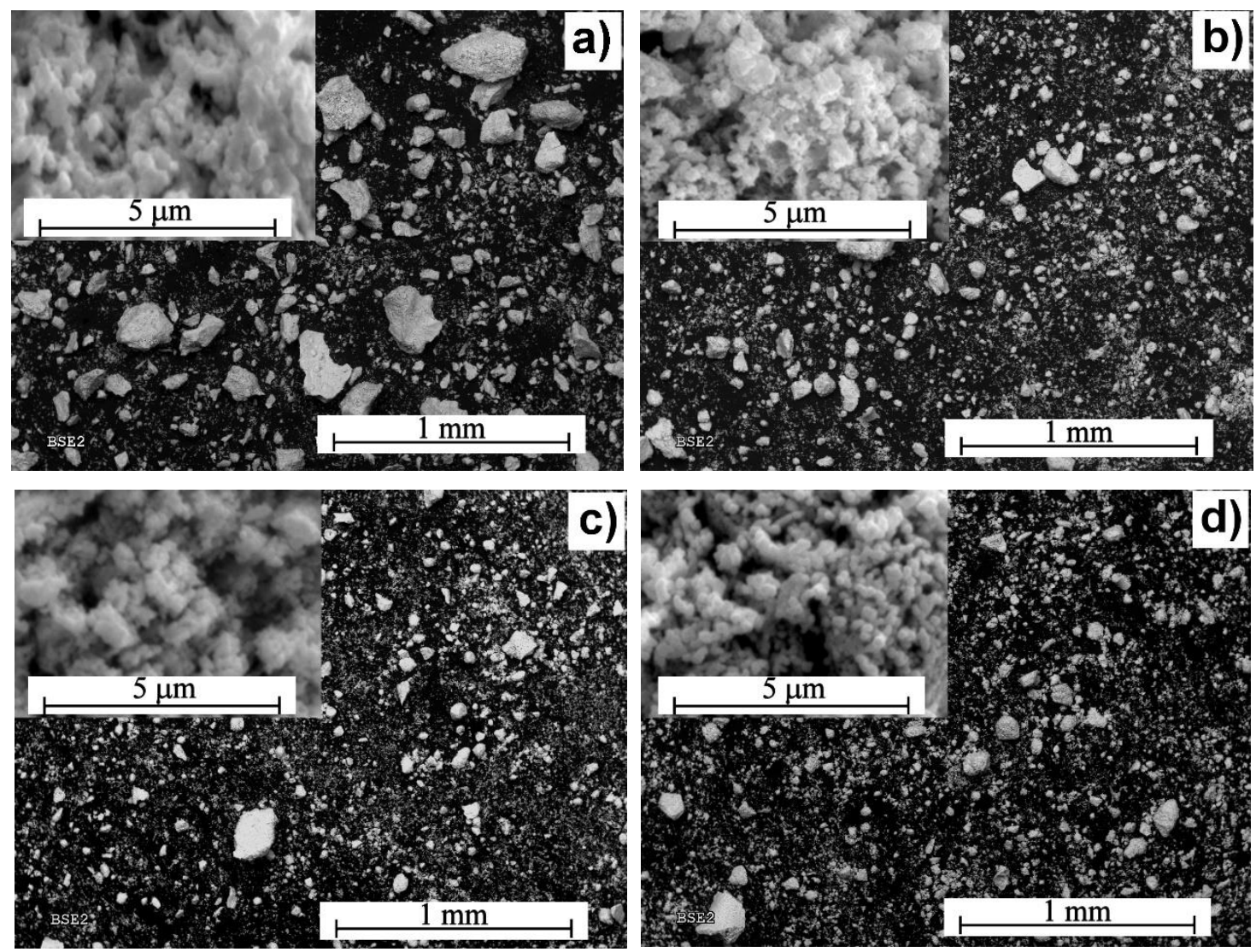

Figure 1. SEM micrographs obtained for: (a) $\mathrm{LaMnO}_{3}$; (b) $\mathrm{LaMn}_{0.8} \mathrm{Co}_{0.2} \mathrm{O}_{3}$; (c) $\mathrm{LaMn}_{0.2} \mathrm{Co}_{0.8} \mathrm{O}_{3}$, and (d) $\mathrm{LaCoO}_{3}$ powders supported on carbon. Magnification: $50 \mathrm{x}$ (main figures) and 10,000x (insets) 


\subsection{Surface chemical composition against bulk composition}

It is known that the surface composition of bimetallic oxides can differ from that of the bulk material. This lack of uniformity can be aggravated by the conditions of synthesis and post-treatment. Therefore, separate surface and bulk analysis is required to study possible differences appearing in $\mathrm{LaMn}_{1-\mathrm{x}} \mathrm{Co}_{\mathrm{x}} \mathrm{O}_{3}$ perovskites. Particularly XPS, as a surface-sensitive probe, can provide fundamental information to distinguish the oxidation state of B-site cations due to its relevance on electrocatalytic properties. Fig. 2 displays La 3d, Mn 2p and Co 2p core-level spectra of samples with increasing Co-substitution. The La 3d region (Fig. 2a) is characterized by two well separated spin-orbit components at around $834 \mathrm{eV}\left(\mathrm{La} \mathrm{3d}_{5 / 2}\right)$ and $851 \mathrm{eV}\left(\mathrm{La} \mathrm{3d}_{3 / 2}\right)$ which further show multiplet structure. Both the peak position and the spin-orbit splitting of La 3d, which is close to $17 \mathrm{eV}$ for all the perovskites of the series, strongly suggest the presence of lanthanum in the trivalent state $[46,47]$. Moreover, the magnitude of the multiplet splitting is higher than $4.0 \mathrm{eV}$ for all the samples, a figure that suggests the presence of lanthanum oxides (other La salts, as hydroxides, show a multiplet splitting under the referenced value [48]). It can be also observed in Fig. 2 a that $\mathrm{La} 3 \mathrm{~d}_{5 / 2}$ and La $3 \mathrm{~d}_{3 / 2}$ peaks shift to lower binding energy at increasing level of cobalt substitution, in agreement with other studies, for which La $3 \mathrm{~d}$ signals in $\mathrm{LaCoO}_{3}$ perovskites appear at lower binding energy than in $\mathrm{LaMnO}_{3}[34,49]$. This observation is usually interpreted in terms of an increase in the electron density around La at higher Co content, which is in turn due to higher backbonding occurring from cobalt than from manganese [49]. 

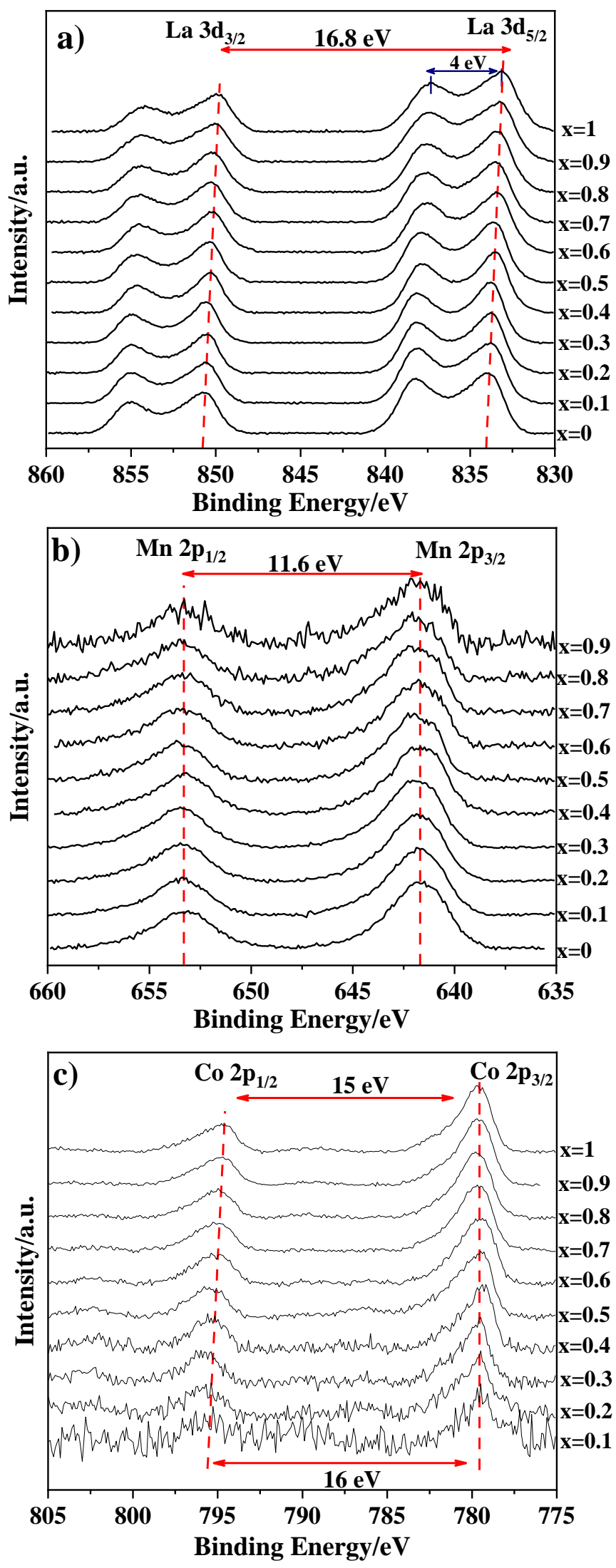

Figure 2. X-ray photoelectron signals obtained from (a) La 3d; (b) Mn 2p and (c) Co 2p spectral regions for different $\mathrm{LaMn}_{1-\mathrm{x}} \mathrm{Co}_{\mathrm{x}} \mathrm{O}_{3}$ perovskites. 
On the other hand, the Mn 2p spectra shown in Fig. 2b presents two spin-orbit signals at about 641.7 and $653.3 \mathrm{eV}$, which are attributed to $\mathrm{Mn} 2 \mathrm{p}_{3 / 2}$ and $\mathrm{Mn} 2 \mathrm{p}_{1 / 2}$, respectively $[46,50]$. The asymmetry of these features suggests the occurrence of more than one oxidation state at the surface. Since the presence of $\mathrm{Mn}^{2+}$ can be discarded due to the lack of satellite features at around $648 \mathrm{eV}$, the surface manganese species should be a mixture of $\mathrm{Mn}^{3+}$ and $\mathrm{Mn}^{4+}$ [51]. In fact, the spin-orbit splitting of the signal, which shows a value close to $11.6 \mathrm{eV}$, is compatible with the presence of both cations [52]. Besides, the Mn 3s core-level spectrum shown in the supplementary information for one of the perovskite samples (Fig. 1S) displays a typical splitting induced by the coupling of $3 \mathrm{~s}$ and $3 \mathrm{~d}$ states $[48,53]$. The magnitude of such splitting strongly suggests the presence of both $\mathrm{Mn}^{3+}$ and $\mathrm{Mn}^{4+}$ species and the absence of $\mathrm{Mn}^{2+}$ on the perovskite surface.

The interpretation of Co $2 p$ spectrum is more complex than that of the two other metal cations. Fig. 2c displays a pair of asymmetrical spin-orbit components easily attributed to Co $2 p_{3 / 2}$ and Co $2 p_{1 / 2}$. The binding energy of the first signal remains almost constant at $779.5 \mathrm{eV}$, irrespective of the relative amount of cobalt in the sample. On the contrary, the Co $2 \mathrm{p}_{1 / 2}$ component shifts to lower binding energy at increasing Co content. As a result, the spin-orbit splitting of Co $2 p$ decreases upon cobalt substitution from almost $16 \mathrm{eV}$ down to $15 \mathrm{eV}$. According to literature, from the binding energy alone it is difficult to clarify the oxidation state of cobalt and it is accepted that a spin-orbit splitting close to 15 $\mathrm{eV}$ can be related to $\mathrm{Co}^{3+}$ species whereas the splitting for $\mathrm{Co}^{2+}$ approximates to $16 \mathrm{eV}$ [54]. Consequently, it can be then deduced from Fig. 2c that, at low cobalt concentration, $\mathrm{Co}^{2+}$ is the main species in $\mathrm{LaMn}_{1-\mathrm{x}} \mathrm{Co}_{\mathrm{x}} \mathrm{O}_{3}$ perovskites and, at higher cobalt substitution, $\mathrm{Co}^{3+}$ predominates.

Obviously, Mn 2p and Co 2p peaks can be deconvoluted to quantify the contribution of each oxidation state to the overall spectrum. Such a result is presented in Fig. 3, where the $\mathrm{Mn} 2 \mathrm{p}_{3 / 2}$ signal was separated into peaks at 641.4 and $643.2 \mathrm{eV}$, and the $\mathrm{Mn} 2 \mathrm{p}_{1 / 2}$ signal gave rise to peaks at 653.0 and $654.6 \mathrm{eV}$ (Fig. 3a). The features at 641.4 and 653.0 $\mathrm{eV}$ can be related to $\mathrm{Mn}^{3+}$ species and those at 643.2 and $654.6 \mathrm{eV}$ to $\mathrm{Mn}^{4+}$ [55]. From the relative peak areas, it can be deduced that the amount of $\mathrm{Mn}^{4+}$ (colored in blue) increases at the expense of $\mathrm{Mn}^{3+}$ (colored in green) at increasing concentration of cobalt. 
In other words, high cobalt substitution promotes the Mn(IV) oxidation state at the perovskite surface. With regard to the Co $2 p$ spectrum in Fig. $3 b$, Co $2 p_{3 / 2}$ and Co $2 p_{1 / 2}$ signals were deconvoluted into two peaks coming from $\mathrm{Co}^{3+}$ (at 779.8 and $794.8 \mathrm{eV}$ ) and from $\mathrm{Co}^{2+}$ (at 781.2 and $796.2 \mathrm{eV}$ ) [56]. It can be observed that $\mathrm{Co}^{3+}$ species (colored in purple) clearly predominate over $\mathrm{Co}^{2+}$ at increasing cobalt substitution. In conclusion, a larger (relative) surface concentration of B cations, either Mn or Co, in their respective higher oxidation states seems favored at increasing levels of cobalt substitution. On the contrary, high manganese content promotes the lower oxidation states of B cations to the perovskite surface. These findings open the possibility of tuning the electrocatalytic behavior of $\mathrm{LaMn}_{1-\mathrm{x}} \mathrm{Co}_{\mathrm{x}} \mathrm{O}_{3}$ materials.
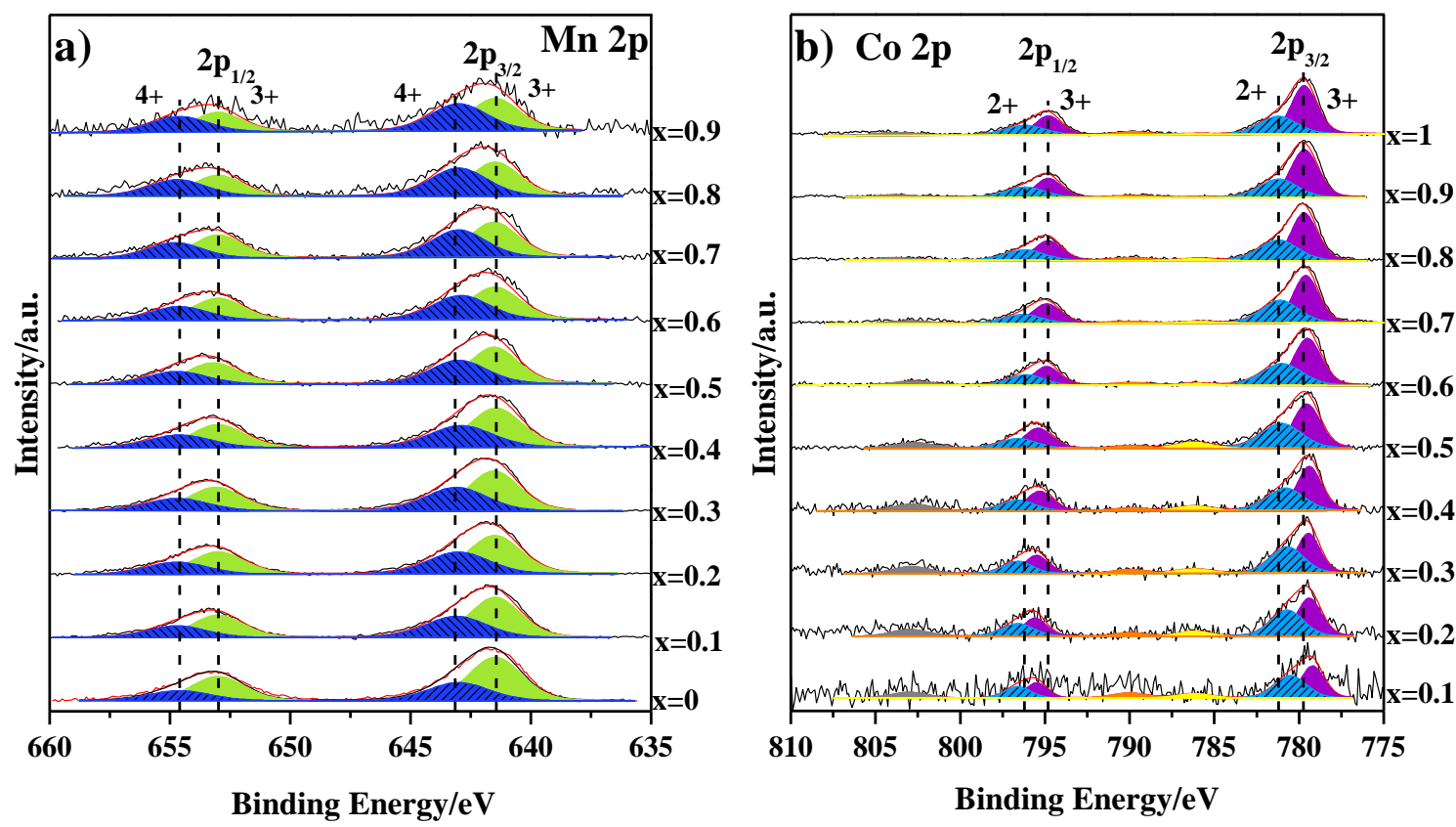

Figure 3. Deconvolution of X-ray photoelectron spectra at (a) Mn 2p and (b) Co $2 p$ spectral regions for $\mathrm{LaMn}_{1-\mathrm{x}} \mathrm{Co}_{\mathrm{x}} \mathrm{O}_{3}$ perovskites.

The bulk composition of perovskites was obtained by EDX analysis and compared with nominal values (coming from the stoichiometry used during the synthesis) and surface composition (coming from XPS results). The results were expressed in terms of $\mathrm{B}_{\text {total }} / \mathrm{A}$ and $\mathrm{B}_{1} / \mathrm{B}_{\text {total }}$ atomic ratios and are summarized in Table 1 . In general, EDX results fit well with nominal values (typically, deviations are under $10 \%$ for $\mathrm{B}_{\text {total }} / \mathrm{A}$ and under $5 \%$ for $\left.\mathrm{B}_{1} / \mathrm{B}_{\text {total }}\right)$, thus confirming the actual composition of the bulk material. However, XPS atomic ratios differ significantly and reveal, on the one hand, that the surface 
concentration of lanthanum almost doubles that of B-site cations and, on the other, that there exists a substantial depletion of surface Co with regard to surface $\mathrm{Mn}$. The phenomenon of surface segregation of cations has been reported frequently in previous studies with different scenarios with a small surface segregation of lanthanum [57] and a surface segregation in the range of 2-5 higher of lanthanum over B-site cation depending on its nature and it is known that could have an impact on the electrocatalytic activity of perovskite oxides due to the role of B-site cation in oxygen reactions [34].

Table 1. Nominal and experimental atomic ratios for $\mathrm{LaMn}_{1-\mathrm{x}} \mathrm{Co}_{\mathrm{x}} \mathrm{O}_{3}$ perovskites obtained from EDX and XPS techniques.

\begin{tabular}{cccccccc}
\hline \multirow{2}{*}{ Sample } & \multicolumn{2}{c}{ Nominal } & \multicolumn{2}{c}{ EDX } & \multicolumn{2}{c}{ XPS } \\
\cline { 2 - 4 } & $\frac{M n+C o}{L a}$ & $\frac{C o}{C o+M n}$ & $\frac{M n+C o}{L a}$ & $\frac{C o}{C o+M n}$ & $\frac{M n+C o}{L a}$ & $\frac{C o}{C o+M n}$ \\
\hline $\mathrm{LaMnO}_{3}$ & 1.00 & 0 & 1.07 & 0.00 & 0.58 & 0.00 \\
$\mathrm{LaMn}_{0.9} \mathrm{Co}_{0.1} \mathrm{O}_{3}$ & 1.00 & 0.10 & 1.05 & 0.10 & 0.54 & 0.06 \\
$\mathrm{LaMn}_{0.8} \mathrm{Co}_{0.2} \mathrm{O}_{3}$ & 1.00 & 0.20 & 0.92 & 0.23 & 0.59 & 0.11 \\
$\mathrm{LaMn}_{0.7} \mathrm{Co}_{0.3} \mathrm{O}_{3}$ & 1.00 & 0.30 & 1.11 & 0.33 & 0.56 & 0.13 \\
$\mathrm{LaMn}_{0.6} \mathrm{Co}_{0.4} \mathrm{O}_{3}$ & 1.00 & 0.40 & 0.89 & 0.43 & 0.58 & 0.17 \\
$\mathrm{LaMn}_{0.5} \mathrm{Co}_{0.5} \mathrm{O}_{3}$ & 1.00 & 0.50 & 1.02 & 0.53 & 0.55 & 0.44 \\
$\mathrm{LaMn}_{0.4} \mathrm{Co}_{0.6} \mathrm{O}_{3}$ & 1.00 & 0.60 & 1.01 & 0.63 & 0.56 & 0.52 \\
$\mathrm{LaMn}_{0.3} \mathrm{Co}_{0.7} \mathrm{O}_{3}$ & 1.00 & 0.70 & 1.09 & 0.72 & 0.51 & 0.62 \\
$\mathrm{LaMn}_{0.2} \mathrm{Co}_{0.8} \mathrm{O}_{3}$ & 1.00 & 0.80 & 0.97 & 0.82 & 0.53 & 0.73 \\
$\mathrm{LaMn}_{0.1} \mathrm{Co}_{0.9} \mathrm{O}_{3}$ & 1.00 & 0.90 & 0.99 & 0.92 & 0.47 & 0.84 \\
$\mathrm{LaCoO}_{3}$ & 1.00 & 1.00 & 1.18 & 1.00 & 0.46 & 1 \\
\hline
\end{tabular}

Hence, the question that arises at this point is whether or not a bulk segregation of phases is at the origin of the surface segregation of cations. To address this issue, a bulk elemental mapping of perovskites can be done by combining SEM images and EDX results. Fig. 4 shows an overlapped SEM-EDX image of the $\mathrm{LaMn}_{0.5} \mathrm{Co}_{0.5} \mathrm{O}_{3}$ perovskite that shows a homogenous distribution of $\mathrm{La}, \mathrm{Mn}$ and $\mathrm{Co}$ cations throughout the material. Similar results were obtained for the rest of perovskites synthesized, thus proving the production of bulk homogenous materials. From this result it can be deduced that neither the surface enrichment in lanthanum nor the depletion of cobalt are related to a segregation of phases within the bulk material. 


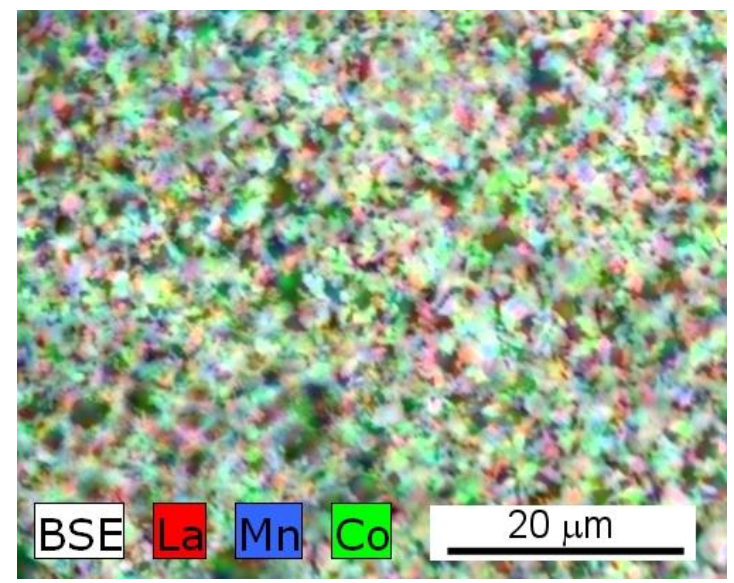

Figure 4. Overlapped SEM-EDX elemental mapping of La (red), Mn (blue) and Co (green) obtained from $\mathrm{LaMn}_{0.5} \mathrm{Co}_{0.5} \mathrm{O}_{3}$ perovskite at $1000 \mathrm{x}$ magnification.

\subsection{Structural characterization}

It is well established that the size of nanoparticles strongly influences the performance of catalysts. Small nanoparticles are usually preferred because they offer larger surface area and, consequently, higher number of accessible active sites. So, to gain insight on both structure and morphology of $\mathrm{LaMn}_{1-\mathrm{x}} \mathrm{Co}_{\mathrm{x}} \mathrm{O}_{3}$ perovskites, a set of these materials was examined by TEM microscopy and the results are presented in the supplementary information (Fig. 2S). The samples show an average particle size that increases from 27 $\mathrm{nm}$ measured for the unsubstituted $\mathrm{LaMnO}_{3}$ sample to almost $60 \mathrm{~nm}$ for the highest level of cobalt substitution, $\mathrm{LaCoO}_{3}$. This result strongly suggests that the presence of cobalt can modify both the structure and morphology of perovskite materials. Since the electrocatalytic activity is influenced by the crystal structure of catalysts, a suitable characterization of these materials should include X-ray diffraction technique. In this way, XRD patterns obtained from $\mathrm{LaMn}_{1-\mathrm{x}} \mathrm{Co}_{\mathrm{x}} \mathrm{O}_{3}$ are presented in Fig. 5, where the crystal structure looks influenced by the cobalt level. The $\mathrm{LaMnO}_{3}$ diffractogram shows reflections at $2 \theta$ values close to $23,33,40,47,58$ and $68^{\circ}$ that can be indexed to a cubic perovskite phase and belongs to the Pm3m space group $\left(\mathrm{LaMnO}_{3}\right.$, PDF code: 01-0750440). Both the position and the relative intensities of these diffraction lines are in agreement with data corresponding to pure $\mathrm{LaMnO}_{3}$. Increasing the Co level up to $\mathrm{x}=0.5$ has little effect on the XRD pattern. However, as the amount of Co exceeds such a value, the lines at $2 \theta$ around $33^{\circ}, 41^{\circ}, 58^{\circ}$, and $68^{\circ}$ split into two peaks, an effect that strongly suggests the formation of a rhombohedral structure. Specifically, the $\mathrm{x}=1$ material shows 
reflections at $2 \theta=23^{\circ}, 33^{\circ}, 41^{\circ}, 48^{\circ}, 59^{\circ}$ and $69^{\circ}$ that can be indexed to the rhombohedral hexagonal $\mathrm{LaCoO}_{3}$ phase belonging to the space group R-3c $\left(\mathrm{LaCoO}_{3}\right.$, PDF code: 00048-0123).

Previous studies [58-60] also reported that $\mathrm{LaMn}_{1-\mathrm{x}} \mathrm{Co}_{\mathrm{x}} \mathrm{O}_{3}$ perovskites are between two different crystal structures, but in those cases, the $\mathrm{LaMnO}_{3}$ perovskite has an orthorhombic structure. The different crystal structure obtained for $\mathrm{LaMnO}_{3}$ might be related with the synthesis method because in those works different methods were used as a classical sol-gel method (without EDTA) [58], an autocombustion method [59] and a coprecipitation method [60]. Therefore, the modified sol-gel method used in our work provides more symmetrical structures that could be beneficial for the electroactivity of the perovskite materials.

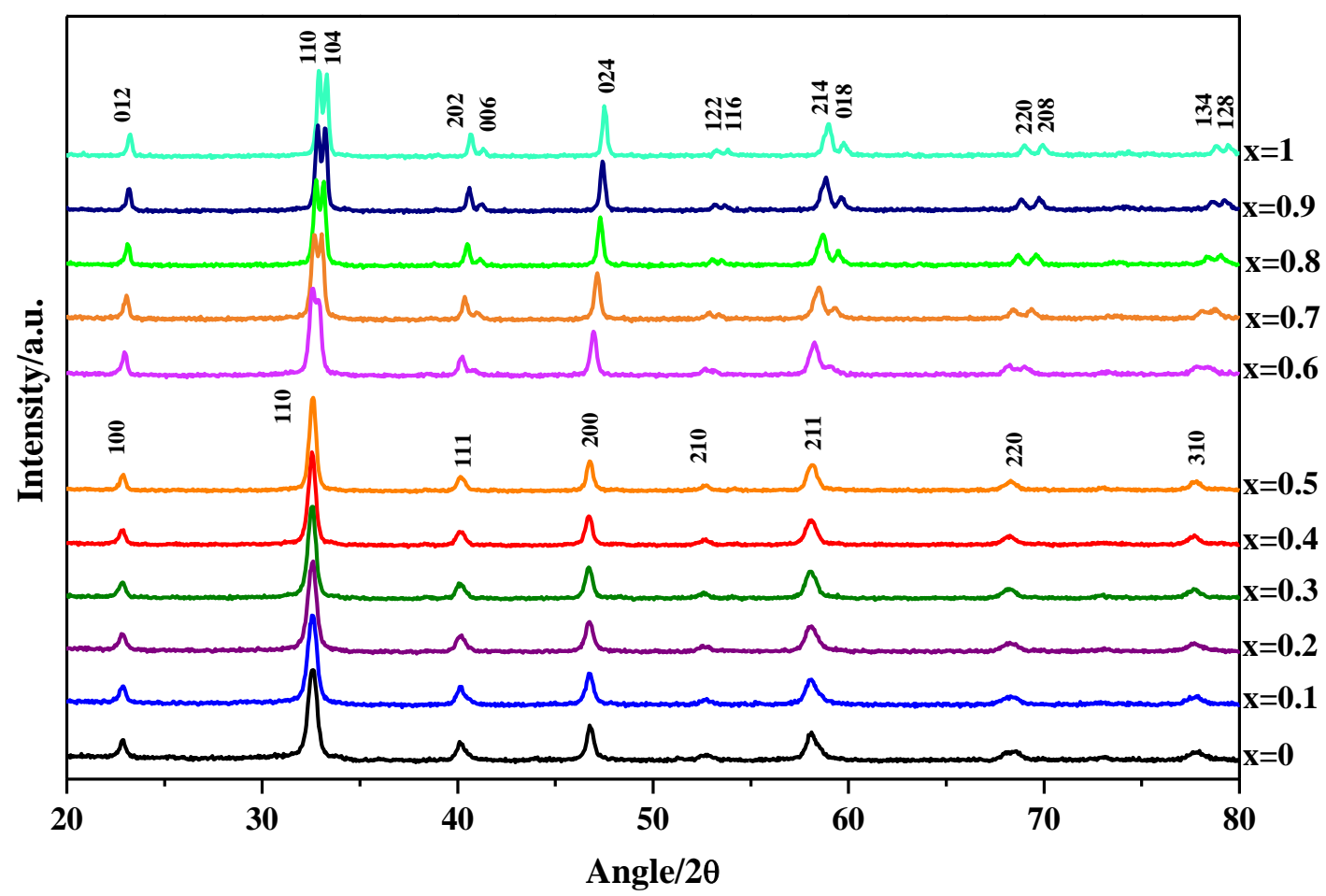

Figure 5. X-ray diffraction patterns for a set of $\mathrm{LaMn}_{1-\mathrm{x}} \mathrm{Co}_{\mathrm{x}} \mathrm{O}_{3}$ perovskites at increasing level of Co-substitution.

On the other hand, the signal at $2 \theta$ around $46^{\circ}-47^{\circ}$ corresponding to the (200) and (024) planes of the cubic and rhombohedral hexagonal structure, respectively, shifts toward higher angles at increasing level of cobalt substitution. Besides, the peak width becomes 
narrower, revealing higher crystallinity at higher relative amount of cobalt, an effect that was reported elsewhere [58]. The lattice parameters of perovskite structures can be calculated using a combination of the following Bragg's equations:

$$
\begin{aligned}
& \mathrm{d}=\frac{\lambda}{2 \sin \theta} \\
& \frac{1}{\mathrm{~d}^{2}}=\frac{\mathrm{h}^{2}+\mathrm{k}^{2}+\mathrm{l}^{2}}{\mathrm{a}^{2}} \\
& \frac{1}{\mathrm{~d}^{2}}=\frac{4}{3} \frac{\left(\mathrm{h}^{2}+\mathrm{hk}+\mathrm{k}^{2}\right)}{\mathrm{a}^{2}}+\frac{\mathrm{l}^{2}}{\mathrm{c}^{2}}
\end{aligned}
$$

where $d$ is the interplanar distance, $(h k l)$ are the Miller indices corresponding to the interplanar distance and $a$ and $c$ are the lattice parameters. In this way, Eqs. 3 and 4 were applied to determine the lattice parameters of cubic structures using the main indexed planes of those perovskites showing $\mathrm{x}<0.6$, whereas Eqs. 3 and 5 were applied to the rhombohedral hexagonal structures (those with $\mathrm{x} \geq 0.6$ ). The average crystallite size was also calculated according to the Scherrer equation by selecting the angles at $22^{\circ}-23^{\circ}$ and $46^{\circ}-47^{\circ}$. The mean crystallographic values obtained from the XRD pattern in Fig. 5 are summarized in Table 2, where specific alterations induced by cobalt can be noted.

\begin{tabular}{|c|c|c|c|c|c|c|}
\hline \multirow{2}{*}{ Unit cell } & \multirow{2}{*}{ Sample } & \multirow{2}{*}{$\begin{array}{c}\text { Crystallite } \\
\text { size }(\mathbf{n m})\end{array}$} & \multicolumn{3}{|c|}{ Lattice parameters } & \multirow{2}{*}{$\begin{array}{c}\text { Lattice } \\
\text { volume }\left(\AA^{3}\right)\end{array}$} \\
\hline & & & $\mathbf{a}$ & $\mathbf{b}$ & $\mathbf{c}$ & \\
\hline \multirow{6}{*}{ Cubic } & $\mathrm{LaMnO}_{3}$ & 21 & 3.885 & 3.885 & 3.885 & 58.638 \\
\hline & $\mathrm{LaMn}_{0.9} \mathrm{Co}_{0.1} \mathrm{O}_{3}$ & 21 & 3.886 & 3.886 & 3.886 & 58.689 \\
\hline & $\mathrm{LaMn}_{0.8} \mathrm{Co}_{0.2} \mathrm{O}_{3}$ & 22 & 3.887 & 3.887 & 3.887 & 58.727 \\
\hline & $\mathrm{LaMn}_{0.7} \mathrm{Co}_{0.3} \mathrm{O}_{3}$ & 22 & 3.888 & 3.888 & 3.888 & 58.782 \\
\hline & $\mathrm{LaMn}_{0.6} \mathrm{Co}_{0.4} \mathrm{O}_{3}$ & 24 & 3.887 & 3.887 & 3.887 & 58.748 \\
\hline & $\mathrm{LaMn}_{0.5} \mathrm{Co}_{0.5} \mathrm{O}_{3}$ & 28 & 3.884 & 3.884 & 3.884 & 58.586 \\
\hline \multirow{5}{*}{ Rhombohedral } & $\mathrm{LaMn}_{0.4} \mathrm{Co}_{0.6} \mathrm{O}_{3}$ & 34 & 5.503 & 5.503 & 13.241 & 400.895 \\
\hline & $\mathrm{LaMn}_{0.3} \mathrm{Co}_{0.7} \mathrm{O}_{3}$ & 32 & 5.485 & 5.485 & 13.179 & 396.453 \\
\hline & $\mathrm{LaMn}_{0.2} \mathrm{Co}_{0.8} \mathrm{O}_{3}$ & 38 & 5.468 & 5.468 & 13.140 & 392.845 \\
\hline & $\mathrm{LaMn}_{0.1} \mathrm{Co}_{0.9} \mathrm{O}_{3}$ & 43 & 5.454 & 5.454 & 13.111 & 390.057 \\
\hline & $\mathrm{LaCoO}_{3}$ & 54 & 5.443 & 5.443 & 13.085 & 387.615 \\
\hline
\end{tabular}

Table 2. Average crystallite size, lattice parameters and unit cell volume for $\mathrm{LaMn}_{1-}$ ${ }_{x} \mathrm{Co}_{\mathrm{x}} \mathrm{O}_{3}$ perovskites obtained from the X-ray diffraction patterns in Fig. 6. 
With regard to average crystallite sizes, it can be clearly observed that their values increase almost uniformly as the cobalt level does. On the contrary, lattice volume data can be divided into two main groups below and above the threshold defined by the $\mathrm{x}=0.5$ sample. This particular cobalt level represents the point from which the rhombohedral structure is formed and, accordingly, the unit cell volume of perovskites multiplies by a factor close to 7 for highly substituted samples.

$\mathrm{Hu}$ et al. [38] suggested that the insertion of cobalt into a $\mathrm{LaMnO}_{3}$ perovskite could take place mainly in the form of $\mathrm{Co}^{2+}$ (which shows an ionic radius $r=74.5 \mathrm{pm}$ [61]) rather than as $\mathrm{Co}^{3+}(r=61 \mathrm{pm})$ at low cobalt concentration. If that was the only factor to take into consideration, increasing the cobalt level would result in a parallel enlargement of the lattice. Therefore, to study more accurately the bulk composition of the $\mathrm{LaMn}_{1-\mathrm{x}} \mathrm{Co}_{\mathrm{x}} \mathrm{O}_{3}$ perovskites several works used XAS techniques $[59,60,62]$ to study the local valence state of the transition metal and observed that, simultaneously to $\mathrm{Co}^{2+}$ insertion, part of $\mathrm{Mn}^{3+}$ $(r=64.5 \mathrm{pm})$ needs to be converted into $\mathrm{Mn}^{4+}(r=53 \mathrm{pm})$ to preserve the electroneutrality of the structure and, accordingly, the bulk (not necessarily the surface) $\mathrm{Mn}^{4+} / \mathrm{Mn}^{3+}$ ratio should increase. Since the size of $\mathrm{Mn}^{4+}$ species is considerable smaller than that of $\mathrm{Mn}^{3+}$, the overall result expected is a slight lattice volume contraction at increasing level of cobalt substitution irrespective of the cell structure adopted. Such a lattice contraction should cause a parallel reduction in the B-O-B angle and, consequently, XRD signals should shift toward higher angles at higher cobalt levels. This is exactly the trend of the rhombohedral structure in Table $2(x \geq 0.6)$ and the shift observed in the diffractograms presented in Fig.5. On the contrary, samples packed in cubic lattices (those for which $\mathrm{x} \leq$ $0.5)$ show almost constant cell volumes. Such an effect was attributed to the progressive depletion of $\mathrm{Mn}^{3+}$ Jahn-Teller species responsible for the lattice deformation, as a result of their conversion into $\mathrm{Mn}^{4+}[58]$.

\section{Conclusions}

A modified sol-gel method has been employed to synthesize $\mathrm{LaMn}_{1-\mathrm{x}} \mathrm{Co}_{\mathrm{x}} \mathrm{O}_{3}$ perovskite catalysts through a sequential substitution of Mn by Co. In front of the classical method which uses only citric acid as the chelating agent, the incorporation of EDTA to the 
synthesis process seems to improve the production of pure perovskite phases, with no single metal oxide impurities $\left(\mathrm{La}_{2} \mathrm{O}_{3}, \mathrm{Mn}_{2} \mathrm{O}_{3}\right.$ or $\left.\mathrm{Co}_{3} \mathrm{O}_{4}\right)$ detected.

It was found that the presence of cobalt leads to similar surface morphology in the obtained materials regardless the extent of Co substitution. However, XRD results and imaging techniques suggested the occurrence of larger particle size at increasing Co level. Significant differences between bulk and surface composition of perovskites were also detected. On the one hand, the surface concentration of B cations in their respective higher oxidation states seems favored at higher levels of cobalt substitution. This phenomenon opens the possibility of tuning the electrocatalytic properties of $\mathrm{LaMn}_{1-\mathrm{x}} \mathrm{Co}_{\mathrm{x}} \mathrm{O}_{3}$ materials. On the other hand, the bulk composition of perovskites is highly homogeneous, irrespective of the cobalt content. Based on this evidence, the observed surface enrichment in lanthanum and the depletion of cobalt versus manganese at increasing cobalt substitution are not related to a bulk segregation of phases.

\section{Conflicts of interest}

There are no conflicts to declare.

\section{Acknowledgments}

The authors thank MINECO and FEDER (MAT2016-76595-R) for the financial support. J.X.F.-L. gratefully acknowledges MINECO for the financial support through FPI contract (BES-2017-081598).

\section{References}

[1] L. Pan, G. Zhu, eds., Perovskite Materials - Synthesis, Characterisation, Properties, and Applications, InTech, 2016. doi:10.5772/60469.

[2] M.L. Medarde, Structural, magnetic and electronic properties of perovskites $(R=$ rare earth), J. Phys. Condens. Matter. 9 (1997) 1679. doi:10.1088/0953$8984 / 9 / 8 / 003$. 
[3] E. Grabowska, Selected perovskite oxides: Characterization, preparation and photocatalytic properties-A review, Appl. Catal. B Environ. 186 (2016) 97-126. doi:10.1016/j.apcatb.2015.12.035.

[4] M. V Kovalenko, L. Protesescu, M.I. Bodnarchuk, Properties and potential optoelectronic applications of lead halide perovskite nanocrystals, 750 (2017) 745-750. doi:10.1126/science.aam7093.

[5] K. Yadav, M.P. Singh, F.S. Razavi, G.D. Varma, Effect of A-site cation size on magnetic and charge-ordering properties of $\mathrm{Ln} 0.5 \mathrm{Sr} 0.5 \mathrm{Mn} 0.9 \mathrm{Cu} 0.1 \mathrm{O} 3(\mathrm{Ln}=\mathrm{La}$, Pr, Nd, or Ho), Mater. Sci. Eng. B Solid-State Mater. Adv. Technol. 177 (2012) 1219-1225. doi:10.1016/j.mseb.2012.06.004.

[6] J. Zhu, H. Li, L. Zhong, P. Xiao, X. Xu, X. Yang, Z. Zhao, J. Li, Perovskite oxides: Preparation, characterizations, and applications in heterogeneous catalysis, ACS Catal. 4 (2014) 2917-2940. doi:10.1021/cs500606g.

[7] M.A. Peña, J.L.G. Fierro, Chemical structures and performance of perovskite oxides, Chem. Rev. 101 (2001) 1981-2017. doi:10.1021/cr980129f.

[8] D. Chen, C. Chen, Z.M. Baiyee, Z. Shao, F. Ciucci, Nonstoichiometric Oxides as Low-Cost and Highly-Efficient Oxygen Reduction/Evolution Catalysts for LowTemperature Electrochemical Devices, Chem. Rev. 115 (2015) 9869-9921. doi:10.1021/acs.chemrev.5b00073.

[9] X. Xu, W. Wang, W. Zhou, Z. Shao, Recent Advances in Novel Nanostructuring Methods of Perovskite Electrocatalysts for Energy-Related Applications, Small Methods. 2 (2018) 1800071. doi:10.1002/smtd.201800071.

[10] L. Zhu, R. Ran, M. Tadé, W. Wang, Z. Shao, Perovskite materials in energy storage and conversion, Asia-Pacific J. Chem. Eng. 11 (2016) 338-369. doi:10.1002/apj.2000.

[11] Z. Yang, J. Zhang, M.C.W. Kintner-meyer, X. Lu, D. Choi, J.P. Lemmon, J. Liu, Electrochemical energy storage for green grid.pdf, Chem. Rev. 111 (2011) 3577613. doi:10.1021/cr100290v.

[12] C. Cui, L. Gan, M. Heggen, S. Rudi, P. Strasser, Compositional segregation in shaped Pt alloy nanoparticles and their structural behaviour during electrocatalysis, Nat. Mater. 12 (2013) 765-771. doi:10.1038/nmat3668. 
[13] X. Yang, L.T. Roling, M. Vara, A.O. Elnabawy, M. Zhao, Z.D. Hood, S. Bao, M. Mavrikakis, Y. Xia, Synthesis and Characterization of Pt-Ag Alloy Nanocages with Enhanced Activity and Durability toward Oxygen Reduction, Nano Lett. 16 (2016) 6644-6649. doi:10.1021/acs.nanolett.6b03395.

[14] Z. Chen, M. Waje, W. Li, Y. Yan, Supportless Pt and PtPd nanotubes as electrocatalysts for oxygen-reduction reactions, Angew. Chemie - Int. Ed. 46 (2007) 4060-4063. doi:10.1002/anie.200700894.

[15] Y. Li, Y. Li, E. Zhu, T. McLouth, C.-Y. Chiu, X. Huang, Y. Huang, Stabilization of High Performance ORR Pt Electrocatalyst Supported on Reduced Graphene Oxide (RGO)/Carbon Black (CB) Composite, J. Am. Chem. Soc. 134 (2012) 12326-12329. doi:10.1021/ja3031449.

[16] T. Reier, M. Oezaslan, P. Strasser, Electrocatalytic oxygen evolution reaction (OER) on Ru, Ir, and pt catalysts: A comparative study of nanoparticles and bulk materials, ACS Catal. 2 (2012) 1765-1772. doi:10.1021/cs3003098.

[17] C.C.L. McCrory, S. Jung, J.C. Peters, T.F. Jaramillo, Benchmarking Heterogeneous Electrocatalysts for the Oxygen Evolution Reaction, J. Am. Chem. Soc. 135 (2013) 16977-16987. doi:10.1021/ja407115p.

[18] J. Du, T. Zhang, F. Cheng, W. Chu, Z. Wu, J. Chen, Nonstoichiometric perovskite $\mathrm{CaMnO}-\delta$ for oxygen electrocatalysis with high activity, Inorg. Chem. 53 (2014) 9106-9114. doi:10.1021/ic501631h.

[19] J. Hu, Q. Liu, Z. Shi, L. Zhang, H. Huang, LaNiO 3 -nanorod/graphene composite as an efficient bi-functional catalyst for zinc-air batteries, RSC Adv. 6 (2016) 86386-86394. doi:10.1039/C6RA16610E.

[20] Y. Xu, A. Tsou, Y. Fu, J. Wang, J.H. Tian, R. Yang, Carbon-Coated Perovskite BaMnO<inf $>3</$ inf $>$ Porous Nanorods with Enhanced Electrocatalytic Perporites for Oxygen Reduction and Oxygen Evolution, Electrochim. Acta. 174 (2015) 551-556. doi:10.1016/j.electacta.2015.05.184.

[21] K. Liu, J. Li, Q. Wang, X. Wang, D. Qian, J. Jiang, J. Li, Z. Chen, Designed synthesis of $\mathrm{LaCoO} / \mathrm{N}$-doped reduced graphene oxide nanohybrid as an efficient bifunctional electrocatalyst for ORR and OER in alkaline medium, J. Alloys Compd. 725 (2017) 260-269. doi:10.1016/j.jallcom.2017.07.178. 
[22] Z. Li, L. Lv, J. Wang, X. Ao, Y. Ruan, D. Zha, G. Hong, Q. Wu, Y. Lan, C.

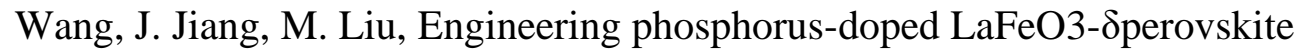
oxide as robust bifunctional oxygen electrocatalysts in alkaline solutions, Nano Energy. 47 (2018) 199-209. doi:10.1016/j.nanoen.2018.02.051.

[23] D.U. Lee, H.W. Park, M.G. Park, V. Ismayilov, Z. Chen, Synergistic bifunctional catalyst design based on perovskite oxide nanoparticles and intertwined carbon nanotubes for rechargeable zinc-air battery applications, ACS Appl. Mater. Interfaces. 7 (2015) 902-910. doi:10.1021/am507470f.

[24] C. Zhu, A. Nobuta, I. Nakatsugawa, T. Akiyama, Solution combustion synthesis of LaMO3 (M = Fe, Co, Mn) perovskite nanoparticles and the measurement of their electrocatalytic properties for air cathode, Int. J. Hydrogen Energy. 38 (2013) 13238-13248. doi:10.1016/j.ijhydene.2013.07.113.

[25] T. Hyodo, M. Hayashi, N. Miura, N. Yamazoe, Catalytic activities of rare-earth manganites for cathodic reduction of oxygen in alkaline solution, J. Electrochem. Soc. 143 (1996) L266-L267. doi:10.1149/1.1837229.

[26] H. Kozuka, K. Ohbayashi, K. Koumoto, Electronic conduction in La-based perovskite-type oxides, Sci. Technol. Adv. Mater. 16 (2015) 26001. doi:10.1088/1468-6996/16/2/026001.

[27] J.S. Griffith, L.E. Orgel, Ligand-Field Theory, (1935). doi:10.1039/qr9571100381.

[28] J.G. Byrne, Printed in the United States Pergamon P r e s s , Inc . ( Received May 9, 1968$), 12$ (1978) 477-479.

[29] J. Suntivich, H.A. Gasteiger, N. Yabuuchi, H. Nakanishi, J.B. Goodenough, Y. Shao-Horn, Design principles for oxygen-reduction activity on perovskite oxide catalysts for fuel cells and metal-air batteries, Nat. Chem. 3 (2011) 546-550. doi:10.1038/nchem.1069.

[30] J. Suntivich, K.J. May, H.A. Gasteiger, J.B. Goodenough, Y. Shao-Horn, A perovskite oxide optimized for oxygen evolution catalysis from molecular orbital principles, Science (80-. ). 334 (2011) 1383-1385. doi:10.1126/science.1212858.

[31] F. Calle-Vallejo, N.G. Inoglu, H.-Y. Su, J.I. Martínez, I.C. Man, M.T.M. Koper, J.R. Kitchin, J. Rossmeisl, Number of outer electrons as descriptor for adsorption 
processes on transition metals and their oxides, Chem. Sci. 4 (2013) 1245. doi:10.1039/c2sc21601a.

[32] J.O. Bockris, The Electrocatalysis of Oxygen Evolution on Perovskites, J. Electrochem. Soc. 131 (1984) 290. doi:10.1149/1.2115565.

[33] J. Sunarso, A.A.J. Torriero, W. Zhou, P.C. Howlett, M. Forsyth, Oxygen reduction reaction activity of La-based perovskite oxides in alkaline medium: A thin-film rotating ring-disk electrode study, J. Phys. Chem. C. 116 (2012) 58275834. doi:10.1021/jp211946n.

[34] V. Celorrio, E. Dann, L. Calvillo, D.J. Morgan, S.R. Hall, D.J. Fermin, Oxygen Reduction at Carbon-Supported Lanthanides: TheRole of the B-Site, ChemElectroChem. 3 (2016) 283-291. doi:10.1002/celc.201500440.

[35] A. Ashok, A. Kumar, R.R. Bhosale, F. Almomani, S.S. Malik, S. Suslov, F. Tarlochan, Combustion synthesis of bifunctional LaMO3(M = Cr, Mn, Fe, Co, $\mathrm{Ni}$ ) perovskites for oxygen reduction and oxygen evolution reaction in alkaline media, J. Electroanal. Chem. 809 (2018) 22-30. doi:10.1016/j.jelechem.2017.12.043.

[36] R.S. Kalubarme, G.-E. Park, K.-N. Jung, K.-H. Shin, W.-H. Ryu, C.-J. Park, LaNixCo1-xO3- Perovskites as Catalyst Material for Non-Aqueous LithiumOxygen Batteries, J. Electrochem. Soc. 161 (2014) A880-A889. doi:10.1149/2.012406jes.

[37] A. Vignesh, M. Prabu, S. Shanmugam, Porous LaCo ${ }_{1-x} \mathrm{Ni}_{x} \mathrm{O}_{3-\delta}$ Nanostructures as an Efficient Electrocatalyst for Water Oxidation and for a Zinc-Air Battery, ACS Appl. Mater. Interfaces. 8 (2016) 6019-6031. doi:10.1021/acsami.5b11840.

[38] J. Hu, L. Wang, L. Shi, H. Huang, Oxygen reduction reaction activity of LaMn1xCoxO3-graphene nanocomposite for zinc-air battery, Electrochim. Acta. 161 (2015) 115-123. doi:10.1016/j.electacta.2015.02.048.

[39] X. Liu, H. Gong, T. Wang, H. Guo, L. Song, W. Xia, B. Gao, Z. Jiang, L. Feng, J. He, Cobalt-Doped Perovskite-Type Oxide LaMnO3as Bifunctional Oxygen Catalysts for Hybrid Lithium-Oxygen Batteries, Chem. - An Asian J. 13 (2018) 528-535. doi:10.1002/asia.201701561. 
[40] D.U. Lee, M.G. Park, H.W. Park, M.H. Seo, V. Ismayilov, R. Ahmed, Z. Chen, Highly active Co-doped $\mathrm{LaMnO} 3$ perovskite oxide and N-doped carbon nanotube hybrid bi-functional catalyst for rechargeable zinc-air batteries, Electrochem. Commun. 60 (2015) 38-41. doi:10.1016/j.elecom.2015.08.001.

[41] X. Ge, F.W.T. Goh, B. Li, T.S.A. Hor, J. Zhang, P. Xiao, X. Wang, Y. Zong, Z. Liu, Efficient and durable oxygen reduction and evolution of a hydrothermally synthesized $\mathrm{La}\left(\mathrm{Co} 0.55 \mathrm{Mn} 0.45\right.$ ) $0.99 \mathrm{O}_{3-\delta}$ nanorod/graphene hybrid in alkaline media, Nanoscale. 7 (2015) 9046-9054. doi:10.1039/C5NR01272D.

[42] C. Li, Z. Yu, H. Liu, K. Chen, High surface area LaMnO 3 nanoparticles enhancing electrochemical catalytic activity for rechargeable lithium-air batteries, J. Phys. Chem. Solids. 113 (2018) 151-156. doi:10.1016/j.jpcs.2017.10.039.

[43] Y. Zhu, R. Tan, Preparation of nanosized $\mathrm{LaCoO} 3$ perovskite oxide using amorphous heteronuclear complex as a precursor at low temperature, J. Mater. Sci. 5 (2000) 5415-5420.

[44] Y. Waseda, E. Matsubara, K. Shinoda, X-Ray Diffraction Crystallography, Springer Berlin Heidelberg, Berlin, Heidelberg, 2011. doi:10.1007/978-3-64216635-8.

[45] X. Liu, H. Gong, T. Wang, H. Guo, L. Song, W. Xia, B. Gao, Z. Jiang, L. Feng, J. He, Cobalt-Doped Perovskite-Type Oxide LaMnO 3 as Bifunctional Oxygen Catalysts for Hybrid Lithium-Oxygen Batteries, Chem. - An Asian J. 13 (2018) 528-535. doi:10.1002/asia.201701561.

[46] C. Zhang, C. Wang, W. Zhan, Y. Guo, Y. Guo, G. Lu, A. Baylet, A. GiroirFendler, Catalytic oxidation of vinyl chloride emission over LaMnO3and LaB0.2Mn0.8O3(B=Co, Ni, Fe) catalysts, Appl. Catal. B Environ. 129 (2013) 509-516. doi:10.1016/j.apcatb.2012.09.056.

[47] M. O’Connell, A.. Norman, C.. Hüttermann, M.. Morris, Catalytic oxidation over lanthanum-transition metal perovskite materials, Catal. Today. 47 (1999) 123132. doi:10.1016/S0920-5861(98)00291-0.

[48] NIST X-ray Photoelectron Spectroscopy Database, Version 4.1 (Web Version), 2012., Http://Srdata.Nist.Gov/Xps/. (n.d.).

[49] X. ZHAO, Q. YANG, J. CUI, XPS study of surface absorbed oxygen of ABO3 
mixed oxides, J. Rare Earths. 26 (2008) 511-514. doi:10.1016/S10020721(08)60128-3.

[50] G. Sinquin, J.P. Hindermann, C. Petit, A. Kiennemann, Perovskites as polyvalent catalysts for total destruction of $\mathrm{C} 1, \mathrm{C} 2$ and aromatic chlorinated volatile organic compounds, Catal. Today. 54 (1999) 107-118. doi:10.1016/S09205861(99)00173-X.

[51] C.L. Li, Y.C. Lin, Methanol partial oxidation over palladium-, platinum-, and rhodium-integrated LaMnO3perovskites, Appl. Catal. B Environ. 107 (2011) 284-293. doi:10.1016/j.apcatb.2011.07.026.

[52] P. Mondal, D. Bhattacharya, A. Maity, O. Chakrabarti, A.K.M. Maidul Islam, M. Mukherjee, Evolution of orbital phases with particle size in nanoscale stoichiometric LaMnO3, J. Appl. Phys. 109 (2011). doi:10.1063/1.3561365.

[53] V.R. Galakhov, M. Demeter, S. Bartkowski, M. Neumann, N.A. Ovechkina, E.Z. Kurmaev, N.I. Lobachevskaya, Y.M. Mukovskii, J. Mitchell, D.L. Ederer, Mn 3 s exchange splitting in mixed-valence manganites, Phys. Rev. B. 65 (2002) 113102. doi:10.1103/PhysRevB.65.113102.

[54] Y. Okamoto, H. Nakano, T. Imanaka, S. Teranishi, X-Ray Photoelectron Spectroscopic Studies of Catalysts-Supported Cobalt Catalysts—, Bull. Chem. Soc. Jpn. 48 (1975) 1163-1168. doi:10.1246/bcsj.48.1163.

[55] Y. Xue, H. Miao, S. Sun, Q. Wang, S. Li, Z. Liu, (La1-xSrx)0.98MnO3perovskite with A-site deficiencies toward oxygen reduction reaction in aluminum-air batteries, J. Power Sources. 342 (2017) 192201. doi:10.1016/j.jpowsour.2016.12.065.

[56] J.L. Gautier, E. Rios, M. Gracia, J.F. Marco, J.R. Gancedo, Characterisation by $\mathrm{X}$-ray photoelectron spectroscopy of thin $\mathrm{MnxCo} 3-\mathrm{xO} 4(1 \geq \mathrm{x} \geq 0)$ spinel films prepared by low-temperature spray pyrolysis, Thin Solid Films. 311 (1997) 5157. doi:10.1016/S0040-6090(97)00463-X.

[57] G. Kéranguéven, C. Ulhaq-Bouillet, V. Papaefthimiou, S. Royer, E. Savinova, Perovskite-carbon composites synthesized through in situ autocombustion for the oxygen reduction reaction: the carbon effect, Electrochim. Acta. 245 (2017) 156164. doi:10.1016/j.electacta.2017.05.113. 
[58] G. Pecchi, C. Campos, O. Peña, L.E. Cadus, Structural, magnetic and catalytic properties of perovskite-type mixed oxides $\mathrm{LaMn} 1$-yCoyO3(y $=0.0,0.1,0.3,0.5$, 0.7, 0.9, 1.0), J. Mol. Catal. A Chem. 282 (2008) 158-166. doi:10.1016/j.molcata.2007.12.022.

[59] M. Ghiasi, M.U. Delgado-Jaime, A. Malekzadeh, R.-P. Wang, P.S. Miedema, M. Beye, F.M.F. de Groot, Mn and Co Charge and Spin Evolutions in LaMn 1- x Co x O 3 Nanoparticles, J. Phys. Chem. C. 120 (2016) 8167-8174. doi:10.1021/acs.jpcc.6b00949.

[60] U.A. Palikundwar, V.B. Sapre, S. V. Moharil, K.R. Priolkar, Local structure around Mn and Co in LaMn 1- x Co x O $3 \pm \delta$ : an EXAFS study, J. Phys. Condens. Matter. 21 (2009) 235405. doi:10.1088/0953-8984/21/23/235405.

[61] R.D. Shannon, Revised Effective Ionic Radii and Systematic Studies of Interatomie Distances in Halides and Chaleogenides of Shannon \& Prewitt [ Acta, Acta. Cryst. 32 (1976) 751-767.

[62] M. Sikora, C. Kapusta, K. Kníźek, Z. Jirák, C. Autret, M. Borowiec, C.J. Oates, V. Procházka, D. Rybicki, D. Zajac, X-ray absorption near-edge spectroscopy study of Mn and Co valence states in LaMn1-x Cox O3 (x=0-1), Phys. Rev. B Condens. Matter Mater. Phys. 73 (2006) 1-5. doi:10.1103/PhysRevB.73.094426. 